\title{
BRINGING UNEMPLOYED BACK TO WORK: EFFECTIVE ACTIVE LABOR MARKET POLICIES*
}

\author{
BY \\ JAN BOONE*****, JAN C. VAN OURS ${ }^{* * *},,^{*}, \dagger \dagger$
}

\begin{abstract}
Summary
We present a theoretical analysis of different types of active labor market policies in the context of a search-matching model. We find that labor market training is effective in bringing down unemployment while public employment services and subsidized jobs are not effective at all. This theoretical finding is confirmed in an explorative empirical analysis using data from 20 OECD countries.
\end{abstract}

Key words: Unemployment, active labor market programs, training, subsidized jobs, public employment services

JEL Code(s): H55, J65, J68

\section{INTRODUCTION}

Unemployment rates are increasing. Average unemployment rate in the OECD increased to 7.8\% April 2009 from 5.6\% 1 year earlier and the expectation is that a further increase lies ahead of us. Naturally, governments worry about the level of unemployment and consider various policy instruments to bring unemployed back to work. Among the policy alternatives active labor market policies (ALMP) are important. ALMP aim at bringing unemployed back to work by improving the functioning of the labor market in various ways. ALMP include programs such as public employment services, labor market training and subsidized employment. The 1994 OECD Jobs study recommends governments to "strengthen the emphasis on active labor market policies and reinforce their effectiveness" (OECD 1994). Recent studies, however, are not very optimistic about the benefits of many

\footnotetext{
* The authors thank Andrea Bassanini and Romain Duval for making their data available. Jan Boone acknowledges financial support from NWO through a Vici grant.

** Department of Economics, CentER, TILEC, Tilburg University, Tilburg, The Netherlands, e-mail: j.boone@uvt.nl.

*** CEPR, London, UK.

$\dagger$ Corresponding author: Department of Economics, CentER, Tilburg University, P.O. Box 90153, 5000 LE, Tilburg, The Netherlands, e-mail: vanours@uvt.nl.

†† Department of Economics, University of Melbourne, Parkville, VIC, Australia.
} 
of these programs. In the reassessment of the Jobs Strategy the OECD concludes "that well-designed programs can have a positive impact (...) but that many existing programs have failed to do so" (OECD 2006). If one would draw a general conclusion from the empirical studies based on micro data it would be that the effects of ALMP on the job finding rates are rather small. An important drawback of a lot of ALMP is that they stimulate workers to reduce their search efforts instead of increasing them. This is due to the socalled locking-in effect (see for example Van Ours 2004). Other effects are important too. What is effective for an individual unemployed worker may not be effective in terms of the aggregate level of unemployment. One reason for this may be crowding out. If a training program brings an unemployed worker back to work more quickly at the expense of another unemployed worker finding a job more slowly the training program is not very efficient. Another reason for the differences between individual and aggregate effects is that a training program may make workers more attractive for firms, which stimulates job creation. Or it may be that a training program induces a better match between a worker and a job. In that case job tenure will increase causing a reduction of unemployment through a reduced inflow into unemployment. This effect is overlooked if one focuses on job finding rates.

There are many evaluation studies. Kluve and Schmidt (2002) use the outcomes of 53 recent evaluation studies to perform a regression where each program represents 1 datapoint. The effects of ALMP are explained by the type of program, the study design (experimental versus non-experimental), the timing (1980s vs. 1990s) and the macroeconomic environment. The authors conclude that programs with a large training content seem to be most likely to improve employment probability. Furthermore, they conclude that both direct job creation and employment subsidies in the public sector almost always seem to fail. Kluve (2007) follows up on this and presents an analysis of about 100 evaluation studies of active labor market policy programs in Europe, most of them operating after 1990. He finds that the effectiveness of programs is quite independent of contextual factors such as labor market institutions and macroeconomic environment. Traditional training programs appear to have at most a modest effect on transitions from unemployment to work private sectors incentive programs. Direct employment programs in the public sector are rarely effective and frequently detrimental for the employment prospects of participants. Card et al. (2009) present an assessment of ALMP based on approximately 200 European and US microeconometrics evaluation studies. The authors find that subsidized public sector employment programs are relatively ineffective. Job search assistance programs have a favorable impact especially in the short run while classroom and on-the-job training programs are not favorable in the short-run, but have more positive impacts after 2 years. 
This paper presents a theoretical analysis of the effectiveness of active labor market policies. We analyze the effects of subsidized jobs, public employment services and labor market training. In this model we introduce some parameters capturing active labor market policies by the government. Training increases the expected productivity of the worker. The government can stimulate training by subsidizing training costs. We also take into account an alternative route to higher productivity. This is through learning on-thejob. The government can stimulate the on-the-job training route by subsidizing the creation of vacancies. Simply because there are more vacancies, unemployed will flow more quickly into jobs and through learning by doing they flow from low productivity to high-productivity jobs (hence the transition from unemployment to high-productivity jobs happens more quickly). Finally, the functioning of the labor market can be influenced through public employment services. These services can influence the labor market because matching becomes more efficient. Our theoretical analysis helps us to explain the dichotomy in the empirical results with micro studies often finding no effect of labor market programs - in particular training programs - while macro studies conclude that these programs do reduce the unemployment rate. Further, we address the empirical puzzle of micro-evaluation studies based on short-term performance of job-related training programs that do not find any strong impact while studies based on longer observations windows tend to present a more optimistic picture (OECD 2005). We find that our model explains the empirical results best if (i) the job finding rate is hardly affected by ALMP, which is consistent with micro studies, and (ii) the main effect of ALMP on unemployment is via job duration. The training component of ALMP scores best because it directly affects this channel while the other measures have only an indirect effect on job duration.

In our explorative empirical analysis we try to find support for our theoretical predictions. We analyze the effects of ALMP on unemployment rates using aggregate time series - cross section data from 20 OECD countries. We find that expenditures on labor market training have an impact on the unemployment rate. Public employment services and subsidized jobs do not seem to affect unemployment rates.

The set-up of the paper is as follows. In Section 2 we present our theoretical model. In Section 3 we discuss our data, the set-up of our analysis and we present parameter estimates. Section 4 concludes.

\section{THE MODEL}

\subsection{The Structure of the Model}

We focus on three types of ALMP: training of unemployed workers (TU), subsidized employment (SE) and public employment services (PES). The 
relationships between specific types of ALMP and parameters in the theoretical model are the following. The effect of training is modeled as a subsidy to training costs of unemployed workers. What we have in mind here is two things. First, placement workers help unemployed workers to find the most suitable courses for them such that they do not waste time and effort enrolling in less effective courses. Second, the government sometimes creates courses that are directly relevant for certain groups of unemployed. This is less costly for the unemployed than doing bits and pieces from different courses, none of which is targeted at them. The effect of employment services is modeled as a subsidy to workers' search costs. Here the placement workers help to filter all vacancy information such that only the vacancies most relevant for an unemployed worker come up. This reduces the search cost for the unemployed. Finally, subsidized employment is modeled as a subsidy for the value of the match of low productivity jobs.

The model introduces two channels through which ALMP can potentially reduce unemployment. First, government measures can increase the job finding rate, that is the speed with which the unemployed flow into employment. Second, through training the unemployed can get better jobs. In particular, we assume that high skilled jobs pay a higher wage and are less likely to be destroyed. Hence if ALMP causes more unemployed to end up in high skilled jobs, it reduces unemployment by decreasing the flow from employment to unemployment. It turns out that the effects of ALMP on the job finding rate are ambiguous theoretically. Moreover, we know from micro studies that the effects on the job finding rate are very small indeed. Hence we focus on the mechanism via the quality of the job and the flow from employment to unemployment. Focussing on this effect, we derive the three basic findings mentioned above including the interaction effect of unemployment benefits and TU on the unemployment rate.

Our model is in the tradition of the search and matching literature, see Mortensen and Pissarides (1999) for an overview. An agent who is unemployed has to decide on two things: search intensity $s$ and training intensity $e$. Search intensity $s$ for a worker yields a disutility of $\gamma(s)$ and a probability of finding a job of $\sin (\theta)$, where $m(\theta)$ denotes the rate with which a worker is matched with a firm as a function of labor market tightness. Labor market tightness $\theta$ is defined as the ratio of vacancies $v$ over effective search by the unemployed $u: \theta \equiv \frac{v}{s u}$. Training intensity $e$ yields a disutility $\chi(e)$ and (conditional on finding a job) a high productivity job with probability $e \in\langle 0,1\rangle$ and a low productivity job with probability $1-e$, where $\chi(0)=0, \chi^{\prime}(e)>0, \chi^{\prime \prime}(e)>0$ and $\chi^{\prime}(0)=0$. The search effort function $\gamma(s)$ features $\gamma(0)=0, \gamma^{\prime}(s)>0, \gamma^{\prime \prime}(s)>0$ and $\gamma^{\prime}(0)=0$. These are fairly standard assumptions for disutility functions.

Let $y_{h}\left(y_{l}\right)$ denote a worker's output in the high (low) productivity job. Further, let $\delta_{l}$ denote the exogenous rate by which a low skilled match 
dissolves. We assume that the corresponding rate for a high skilled job is smaller, $\delta_{h}<\delta_{l}$. Note that this is consistent with empirical evidence that job separation rates decline with the skill of workers (see for example OECD 1997). Finally, $\varepsilon \geq 0$ denotes the exogenous probability that a worker in a low productivity job, through learning by doing, ends up in a high productivity job.

The Bellman equations for workers in this case become:

$$
\begin{aligned}
& \rho V_{u}=\max _{s, e}\left\{\begin{array}{c}
b-\kappa-\left(1-\sigma_{\gamma}\right) \gamma(s)-\left(1-\sigma_{\chi}\right) \chi(e) \\
+s m(\theta)\left[e V_{h}+(1-e) V_{l}-V_{u}\right]
\end{array}\right\} \\
& \rho V_{h}=w_{h}+\delta_{h}\left(V_{u}-V_{h}\right) \\
& \rho V_{l}=w_{l}+\varepsilon\left(V_{h}-V_{l}\right)+\delta_{l}\left(V_{u}-V_{l}\right)
\end{aligned}
$$

where $\rho$ denotes the discount rate, $V_{u}$ the expected discounted value of being unemployed, $V_{h}\left(V_{l}\right)$ the value of having a high (low) productivity job. The policy instruments $\sigma_{\gamma}, \sigma_{\chi} \in[0,1]$ denote the reduction in search costs due to PES and the reduction in workers' training costs due to TU. The parameter $\kappa \geq 0$ denotes the negative effect (if any) of being in an ALMP program. This can be a stigma effect or the disutility of being monitored in a training or PES program. Hence $\kappa=0$ if there is no program to participate in.

The value of being unemployed $\rho V_{u}$ equals the sum of four terms. There is unemployment benefit level $b$ reduced by the effort costs of search and training and the stigma disutility if the worker participates in ALMP. Then there is the probability $\operatorname{sm}(\theta)$ of finding a job and leaving unemployment. With probability $e(1-e)$ the worker finds a high (low) productivity job with corresponding expected discounted pay offs $V_{h}\left(V_{l}\right)$. The value of having a high productivity job $\rho V_{h}$ equals the wage $w_{h}$ you earn until (with probability $\delta_{h}$ ) the match is dissolved and you become unemployed again. The value of a low productivity job $\rho V_{l}$ is comparable except that now there is a probability $\varepsilon$ that by learning by doing the low productivity job turns into a high productivity job. Hence we assume that there is no ex ante variation in skills (everyone has the same disutility function $\chi(e)$ ). Further, if a worker loses his job and does not invest in training (e) while unemployed, he loses his skills.

The participation of agents in the labor market is determined by the value of their outside opportunities $\omega$. Outside opportunities include value of leisure, home production, taking care of the children etc. We assume that $\omega$ is distributed on $[\omega, \bar{\omega}]$ with distribution function $F(\omega)$ and we normalize the size of the population at 1 (i.e. $F(\bar{\omega})=1$ ). An agent only joins the labor market if the value of doing so exceeds the outside opportunity of staying at home: $\rho V_{u} \geq \omega$. Hence we assume that people cannot find a job right away when they are outside of the labor force. If an agent wants to work, he first becomes unemployed and then finds a job. Because of this assumption, the relevant comparison is between $\omega$ and $\rho V_{u}$. It follows that the participation 
rate (fraction of the population participating in the labor market) is given by $l=F\left(\rho V_{u}\right)$. Further total unemployment is given by $F\left(\rho V_{u}\right) u$ and the employment population rate equals $e p=F\left(\rho V_{u}\right)(1-u)$.

Turning to the other side of the labor market, the Bellman equations for firms can be written as follows.

$$
\begin{aligned}
& \rho J_{v}=-c+\frac{m(\theta)}{\theta}\left(e J_{h}+(1-e) J_{l}-J_{v}\right) \\
& \rho J_{h}=y_{h}-w_{h}+\delta_{h}\left(J_{v}-J_{h}\right) \\
& \rho J_{l}=y_{l}+\sigma_{y_{l}}-w_{l}+\varepsilon\left(J_{h}-J_{l}\right)+\delta_{l}\left(J_{v}-J_{l}\right)
\end{aligned}
$$

where $J_{v}$ is the value for a firm of posting a vacancy, $J_{h}\left(J_{l}\right)$ denotes the value of the firm matched with a worker in the high (low) productivity state. The cost of opening a vacancy equals $c$. The probability that the firm's vacancy is matched with a worker equals $\frac{m(\theta)}{\theta}$ and is decreasing in tightness $\theta$. The probability that a vacancy is matched with a high (low) skilled worker equals $\frac{m(\theta)}{\theta} e\left(\frac{m(\theta)}{\theta}(1-e)\right)$. The probabilities $\delta_{l}, \delta_{h}$ and $\varepsilon$ are the same as the ones above in the worker's problem. The job subsidy given by the government takes the form here of increasing the value of the match in the low productivity state by $\sigma_{y_{l}}$. We assume that the government does not subsidize high productivity jobs, as indeed governments target such subsidies at the bottom of the labor market. As usual, we assume that there is free entry in posting vacancies and hence $J_{v}=0$.

Finally, we have the following equations of motion for the unemployment rate, percentage of participating workers in high productivity jobs and low productivity jobs.

$$
\begin{aligned}
\dot{u}_{t} & =\delta_{h} n_{h t}+\delta_{l} n_{l t}-s_{t} m\left(\theta_{t}\right) u_{t} \\
\dot{n}_{h t} & =-\delta_{h} n_{h t}+\varepsilon n_{l t}+s_{t} m\left(\theta_{t}\right) e_{t} u_{t} \\
n_{l t} & =1-\left(u_{t}+n_{h t}\right)
\end{aligned}
$$

Note that because of the assumption of linear vacancy costs, the size of the labor market $F\left(\rho V_{u}\right)$ has no effect on the unemployment and employment rates. In steady state the unemployment rate is given by

$$
u=\frac{1}{1+\frac{s m(\theta)}{\delta_{h}\left(\varepsilon+\delta_{l}\right)}\left(\delta_{h}+\varepsilon+e\left(\delta_{l}-\delta_{h}\right)\right)}
$$

Hence an increase in the job finding rate $\operatorname{sm}(\theta)$ and in the training effort $e$ reduce the steady state unemployment level. The former through increasing the flow from unemployment to employment, the latter through reducing the flow in the opposite direction. 


\subsection{Solving The Model}

In this section, we solve the model for search effort $s$, training effort $e$ and the participation rate $F\left(\rho V_{u}\right)$. To do this we start by deriving the wages for high and low productivity jobs.

We assume that workers and firms Nash bargain about the wage in each state. That is $w_{h}$ and $w_{l}$ solve respectively

$$
\begin{gathered}
\max _{w_{h}}\left(V_{h}-V_{u}\right)^{1-\beta}\left(J_{h}\right)^{\beta} \\
\max _{w_{l}}\left(V_{l}-V_{u}\right)^{1-\beta}\left(J_{l}\right)^{\beta}
\end{gathered}
$$

This leads to the following well known expressions for the wage rates.

Lemma 1 The wages equal

$$
\begin{aligned}
w_{h} & =(1-\beta) y_{h}+\beta \rho V_{u} \\
w_{l} & =(1-\beta)\left(y_{l}+\sigma_{y_{l}}\right)+\beta \rho V_{u}
\end{aligned}
$$

With these wages, we can determine $V_{u}, V_{h}, V_{l}, J_{h}$ and $J_{l}$. The next result shows the equations determining $s, e, \rho V_{u}$ and $\theta$.

Lemma 2 The first order conditions for training and search intensity of an individual can be written as

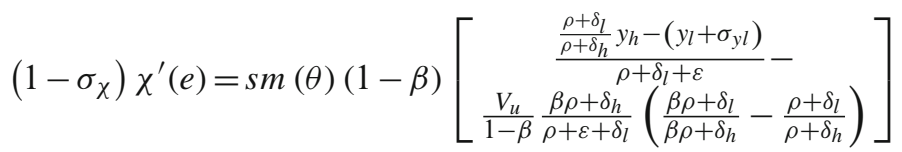

$$
\begin{aligned}
& \left(1-\sigma_{\gamma}\right) \gamma^{\prime}(s)=(1-\beta) m(\theta)\left[\frac{y_{h}-\rho V_{u}}{\rho+\delta_{h}}+(1-e)\right. \\
& \left.\times\left[\begin{array}{c}
-\frac{\frac{\rho+\delta_{l}}{\rho+\delta_{h}} y_{h}-\left(y_{l}+\sigma_{y l}\right)}{\rho+\delta_{l}+\varepsilon}+ \\
\frac{V_{u}}{1-\beta} \frac{\beta \rho+\delta_{h}}{\rho+\varepsilon+\delta_{l}}\left(\frac{\beta \rho+\delta_{l}}{\beta \rho+\delta_{h}}-\frac{\rho+\delta_{l}}{\rho+\delta_{h}}\right)
\end{array}\right]\right]
\end{aligned}
$$

The value of being unemployed is determined by

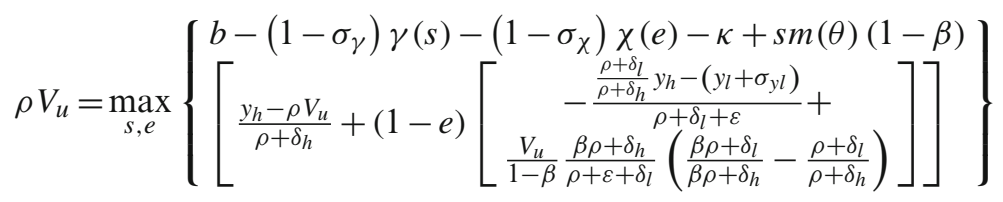


Finally, labor market tightness is determined by

$$
\theta=\frac{\beta\left(1-\sigma_{\gamma}\right)}{(1-\beta) c} \gamma^{\prime}(s)
$$

As one can verify, these equations follow from the Bellman equations above. First, consider the effects of the instruments $\sigma_{\gamma}, \sigma_{\chi}$ and $\sigma_{y l}$ on the job finding rate $\operatorname{sm}(\theta)$. We argue that these effects are theoretically ambiguous: the effect can be positive and negative depending on which effect dominates. Therefore we should not be surprised if no clear effect is found in the data of these measures on the job finding rate. As $\sigma_{\gamma}$ is raised, the marginal costs of search go down. Thus there is a tendency for the unemployed to search more. However, the rise in $\sigma_{\gamma}$ also reduces the level of search costs and hence raises the value of being unemployed. This leads to a locking in effect. As being unemployed is not so bad anymore, there is less incentive to escape unemployment through search and/or training. The locking in effect leads to lower search and training intensities which both tend to raise unemployment. A similar ambiguity is found in the case of TU. On the one hand, a rise in $\sigma_{\chi}$ reduces marginal training costs and hence stimulates training effort. Since this raises the probability of finding a high wage job, it also stimulates search. On the other hand, the following locking in effect is present. By reducing the level of training costs, the value of being unemployed goes up. This reduces the incentive to find a job. Finally, consider SE, parameterized here as a rise in $\sigma_{y l}$. This raises the pay off in low wage jobs and hence stimulates search. But by reducing the wage differential between high and low skilled jobs, it reduces training intensity. This decreases the probability of getting a high wage job, an effect that reduces search and the job finding rate.

These ambiguous theoretical effects of ALMP instruments on the job finding rate are reminiscent of empirical studies on micro data which do not find strong effects either of ALMP on the job finding rate. These studies are discussed in more detail below. Beside the ambiguous theoretical results above, another reason for such empirical findings can be that search is rather inelastic (i.e. $\gamma^{\prime \prime}(s)$ is big).

Since the empirical literature indicates (and we find this in the data as well) that some ALMP instruments reduce unemployment, but do not wish to rely on a theoretical explanation that is contradicted by micro evidence (which rules out that ALMP instruments reduce unemployment by raising the job finding rate), we analyze the model above under the assumption that the effects on the job finding rate $\operatorname{sm}(\theta)$ are small. Put differently, we assume that the effects of ALMP on the job finding rate are dominated by the effects outlined below which focus on the quality of the job found by the unemployed. To do this, we assume that search $\bar{s}$, tightness $\bar{\theta}$ and thus the job 
finding rate $\bar{s} m(\bar{\theta})$ are exogenously fixed. The following proposition characterizes the effects of ALMP and unemployment benefits in this case. ${ }^{1}$ Proof of the proposition can be found in the Appendix.

Proposition 1 For given job finding rate $\bar{s} m(\bar{\theta})$, we find the following effects in the model:

$\frac{\partial V_{u}}{\partial \sigma_{\gamma}}, \frac{\partial V_{u}}{\partial \sigma_{\chi}}, \frac{\partial V_{u}}{\partial \sigma_{y l}}>0, \frac{\partial V_{u}}{\partial \kappa}<0$ and $\frac{\partial V_{u}}{\partial b}>0$;

$\frac{\partial e}{\partial \sigma_{\gamma}}, \frac{\partial e}{\partial \sigma_{y l}}<0, \frac{\partial e}{\partial \sigma_{\chi}}>0, \frac{\partial e}{\partial \kappa}>0$ and $\frac{\partial e}{\partial b}<0$;

$\frac{\partial u}{\partial \sigma_{\gamma}}, \frac{\partial u}{\partial \sigma_{y l}}>0, \frac{\partial u}{\partial \sigma_{\chi}}<0, \frac{\partial u}{\partial \kappa}<0$ and $\frac{\partial u}{\partial b}>0 ;$

$\frac{\partial\left((1-u) F\left(\rho V_{u}\right)\right)}{\partial \sigma_{\chi}}>0$;

finally, $\frac{\partial^{2} u}{\partial \sigma_{\chi} \partial b}<0$ if $\chi^{\prime \prime \prime}(e)>0$ is big enough.

Hence all three programs increase the value of being unemployed. However, if the program causes a stigma effect, it reduces the value of being unemployed. Similarly, an increase in the unemployment benefit raises the value of being unemployed. These effects of $\sigma_{\gamma}$ and $\sigma_{\chi}$ on $V_{u}$ are the locking in effects described above.

Next consider the effects of the three instruments on training effort $e$ and thereby (since $\bar{s} m(\bar{\theta})$ is given) on the unemployment rate. The effect on the unemployment rate has the opposite sign from the effect on training $e$ since more training leads to a higher probability of finding a high skilled job which has a lower separation rate. Hence unemployment goes down, as $e$ goes up by reducing the outflow from employment into unemployment.

An increase in $\sigma_{\gamma}$ does not directly affect the incentive to train, but it does raise the value of being unemployed. As the value of being unemployed is increased, getting a job with a higher separation rate is less of a problem. Hence the incentive to train is reduced. Via this mechanism PES raises unemployment. To the extent that participating in a PES program introduces a stigma effect ( $\kappa$ goes up), it tends to reduce unemployment by decreasing the value of being unemployed and therefore stimulating training.

Introducing SE for low skilled jobs, reduces the incentive to get a high skilled job by decreasing the wage differential. As shown in Lemma 1, $w_{h}-w_{l}$

1 We use the comparative statics in the proposition to understand the patterns we find in the data. Thus we do not consider explanations which start from an exogenous change in, say, the government's preferences which leads the government to optimally change its instruments. This would introduce an endogeneity in the instruments that is beyond the scope of this paper. Instead, we view governments as inventing and experimenting with different ALMP instruments. In this sense, we view changes in the instruments as exogenous. 
falls with $\sigma_{y l}$. Hence training effort goes down and unemployment goes up. It is not clear whether there would be a stigma $(\kappa)$ effect in this case working in the opposite direction. Similarly, an increase in unemployment benefits reduces training and hence raises unemployment.

Further, consider the effect of $\mathrm{TU}$ on training intensity. By reducing the marginal costs of training, an increase in $\sigma_{\chi}$ raises training effort. On the other hand, $\sigma_{\chi}$ also reduces the level of training costs and hence raises the value of being unemployed. This tends to reduce training effort. As we show in the Appendix, under the assumptions made above, the former effect always dominates the latter. The intuition for this is discounting $(\rho>0){ }^{2}$

The direct reduction of marginal training costs due to the increase in $\sigma_{\chi}$ happens now and is not discounted. The increase in $V_{u}$ which reduces the future (after the worker has found a job) wage differential $w_{h}-w_{l}$ comes in in a discounted way and hence weighs less. Therefore the direct effect outweighs the indirect effect of $\sigma_{\chi}$. Hence, a rise in $\sigma_{\chi}$ stimulates training and reduces unemployment. And because $\sigma_{\chi}$ raises $V_{u}$ and thus the gross participation rate $F\left(\rho V_{u}\right)$, we find that TU unambiguously raises the employment population rate. In the other cases, we do not get such an unambiguous result. Not even if we use the stigma effect $\kappa$. The effect of $\kappa$ is to reduce $V_{u}$ and thereby stimulate training, but it also directly reduces participation $F\left(\rho V_{u}\right)$.

Summarizing, focussing on the quality of the job and assuming that the effects of ALMP on the job finding rate are small, we find the following effects. First, TU by directly stimulating training effort and by raising the value of being unemployed reduces the unemployment rate and raises the employment-population rate. The direct effect of PES on training is to reduce it, thereby raising unemployment. If PES causes a stigma effect, it reduces the value of being unemployment, thereby stimulating training and reducing unemployment. However, the reduction in $V_{u}$ then reduces participation and hence we get an ambiguous effect on the employment-population rate. The direct effect of SE on training is to reduce it and hence it tends to raise unemployment. But the effect on the employment-population rate is ambiguous, since $\mathrm{SE}$ raises $V_{u}$ and hence stimulates participation.

Finally, we find that an increase in $b$ makes the training subsidy more effective in reducing unemployment. The main effect is that by raising $b$, training effort goes down $\left(\frac{\partial e}{\partial b}<0\right)$ and therefore the unemployed moves to a part of the effort cost function $\chi($.$) that is more elastic (here we use the$ assumption that $\left.\chi^{\prime \prime \prime}(e)>0\right)$. This effect dominates other effects if $\chi^{\prime \prime \prime}(e)$ is big enough. The idea is that if the worker invests already a lot in training,

2 Note that the proof in the Appendix relies on the fact that $\frac{(1-\beta) \rho}{\rho+\delta_{h}}-\frac{\beta \rho+\delta_{h}}{\rho+\delta_{l}}$ $\left(\frac{\beta \rho+\delta_{l}}{\beta \rho+\delta_{h}}-\frac{\rho+\delta_{l}}{\rho+\delta_{h}}\right)>0$ which follows from $\rho>0$. 
a subsidy will increase this effort further but not by much. The marginal training costs are already so high, that further increases in effort are hard to realize. But higher unemployment benefits imply a lower training effort and hence there is more room to increase effort further. Another effect is that the effect of an increase in training $e$ on unemployment $u$

$$
\frac{\partial u}{\partial e}=\frac{-\frac{s m(\theta)}{\delta_{h}\left(\varepsilon+\delta_{l}\right)}\left(\delta_{l}-\delta_{h}\right)}{\left(1+\frac{s m(\theta)}{\delta_{h}\left(\varepsilon+\delta_{l}\right)}\left(\delta_{h}+\varepsilon+e\left(\delta_{l}-\delta_{h}\right)\right)\right)^{2}}
$$

is big in absolute value if the denominator is small. The denominator is small if $e$ is small, which is exactly what a high value of $b$ establishes. In other words, if $e$ is small, unemployment is rather high and reducing it is relatively easy. Hence for higher $b$ the increase in $e$ (due to a rise in $\sigma_{\chi}$ ) has a bigger effect on unemployment $u$.

\section{AN EXPLORATIVE EMPIRICAL ANALYSIS}

\subsection{Previous Studies}

Empirical work on the macroeconomic effects of ALMP is rare. And, often no distinction is made between types of ALMP. Instead, the focus is on total ALMP-expenditures. The equation of interest usually exploits cross-country variation in unemployment and ALMP-expenditures. In a general form, such an equation can be specified as follows:

$$
u_{i t}=\alpha_{i}+\alpha_{t}+\beta_{0}+\beta_{1} x_{i t}+\beta_{2} y_{i t}+\beta_{3} z_{i t}+\varepsilon_{i t}
$$

where $u_{i t}$ is the unemployment rate (unemployment as a percentage of the labor force) in country $i$ and calendar year (or time period) $t$. Furthermore, the $\alpha_{i}$ represent country fixed effects, the $\alpha_{t}$ represent calendar year fixed effects, $x$ is a vector of labor market institutions, $y$ refers to ALMP-expenditures and $z$ is a vector of macroeconomic indicators representing cyclical influences. Finally, $\varepsilon_{i t}$ is the error term. With one exception which will be discussed below, none of the empirical studies uses a fixed effects specification.

There is a limited number of empirical studies using cross-country time series information to establish the effects of ALMP. Scarpetta (1996) uses annual data from 17 countries over the 1983-1993 period. As the ALMPvariable he uses the expenditures on active measures per unemployed person relative to GDP per capita. He finds that ALMP have a negative impact on the unemployment rate but there are also indications of large substitution and displacement effects on employment. There is a positive correlation between ALMP and the employment-population rates, which indicates that these policies have a positive effect on labor force participation by keeping 
otherwise discouraged workers in the labor force. Elmeskov et al. (1998) analyze annual data from 19 countries over the period 1983-1995. Again the ALMP variable is the public spending on ALMP per unemployed person relative to GDP per capita. The authors conclude that ALMP have a statistically significant negative effect on the unemployment rate. Nickell and Layard (1999) analyze 6 years period averages from 20 OECD countries over the period 1983-1994. The ALMP-variable is the ALMP spending per unemployed person as a percentage of GDP per member of the labor force. The authors find that ALMP have a negative effect on long-term unemployment but no significant effect on the employment-population rate. Blanchard and Wolfers (2000) have 5 years averages data on 20 OECD countries and analyze the period 1960-1995. As they use a time-invariant country-specific average ALMP-variable and include country fixed effects they cannot identify the direct effect of ALMP on the unemployment rate. Instead, they study the interaction between ALMP and shocks concluding that higher expenditures on ALMP reduce the effects of shocks on unemployment.

The studies that have been performed do not all point in the same direction. Scarpetta (1996), Elmeskov et al. (1998), and Nickell and Layard (1999) find that ALMP reduce the unemployment rate. Only Scarpetta (1996) finds that ALMP increase the employment-population rate.

\subsection{Data}

The OECD has systematic information about ALMP since 1985. The expenditures are measured as a percentage of GDP and as shown in Table 1 there are clear differences between countries. Whereas Japan only spends $0.03 \%$ of GDP on labor market training, Denmark spends $0.63 \%$. While the US spends $0.06 \%$ of GDP on PES and countries like Greece, Portugal and Spain spend $0.9 \%$ of GDP on this ALMP, The Netherlands spend $0.34 \%$ of their GDP on PES. ${ }^{3}$ Also with respect to expenditures on subsidized jobs the differences between countries are quite large. The US spend $0.01 \%$ of GDP on subsidized jobs, while Belgium spends $0.72 \%$ of their GDP on subsidized jobs. These differences appear both in terms of levels as well as developments. In Denmark for example public expenditures on labor market training went up from $0.37 \%$ in the second half of the 1980 s to $0.99 \%$ in the second half of the 1990 s. In the same time in Ireland these expenditures went down from 0.53 to $0.21 \%$. In Sweden the expenditures first went up from $0.51 \%$ in the second half of the 1980 s to $0.82 \%$ in the early 1990 s and went back again to $0.55 \%$ in the second half in the 1990s. At the lower end for example is Japan where

3 Note that one should be cautious in interpreting results for PES since they include also administrative costs. An increase in efficiency through cuts in red tape will reduce expenditures on PES but not the potential effectiveness. 
TABLE 1 - PUBLIC EXPENDITURES ON CATEGORIES OF ALMP; AVERAGES $(\%$ of GDP)

\begin{tabular}{lllllll}
\hline & Training & PES & $\begin{array}{l}\text { Subsidized } \\
\text { jobs }\end{array}$ & Other & Total & Time period \\
& & & & & \\
\hline 1. Australia & 0.07 & 0.17 & 0.13 & 0.11 & 0.48 & $1985-2001$ \\
2. Austria & 0.13 & 0.12 & 0.06 & 0.07 & 0.38 & $1985-2002$ \\
3. Belgium & 0.24 & 0.19 & 0.72 & 0.15 & 1.30 & $1985-2001$ \\
4. Canada & 0.24 & 0.22 & 0.04 & 0.03 & 0.53 & $1985-2001$ \\
5. Denmark & 0.63 & 0.10 & 0.30 & 0.44 & 1.47 & $1986-2000$ \\
6. Finland & 0.36 & 0.13 & 0.52 & 0.24 & 1.25 & $1985-2002$ \\
7. France & 0.32 & 0.15 & 0.25 & 0.36 & 1.08 & $1985-2001$ \\
8. Germany & 0.35 & 0.22 & 0.31 & 0.30 & 1.18 & $1985-2002$ \\
9. Ireland & 0.37 & 0.20 & 0.43 & 0.44 & 1.44 & $1985-91$, \\
& & & & & & $1994-96,2001$ \\
10. Italy & 0.07 & 0.02 & 0.18 & 0.06 & 0.33 & $1991-2001$ \\
11. Japan & 0.03 & 0.16 & 0.07 & 0.01 & 0.27 & $1987-2001$ \\
12. Netherlands & 0.34 & 0.34 & 0.17 & 0.66 & 1.51 & $1985-2002$ \\
13. New Zealand & 0.34 & 0.13 & 0.19 & 0.12 & 0.78 & $1985-2001$ \\
14. Norway & 0.16 & 0.14 & 0.12 & 0.44 & 0.86 & $1985-2002$ \\
15. Portugal & 0.21 & 0.09 & 0.07 & 0.29 & 0.66 & $1986-2000$ \\
16. Spain & 0.15 & 0.09 & 0.34 & 0.09 & 0.67 & $1985-2002$ \\
17. Sweden & 0.55 & 0.26 & 0.42 & 0.81 & 2.04 & $1985-2001$ \\
18. Switzerland & 0.07 & 0.10 & 0.08 & 0.16 & 0.41 & $1985-2002$ \\
19. United Kingdom & 0.10 & 0.18 & 0.08 & 0.21 & 0.57 & $1985-2001$ \\
20. United States & 0.06 & 0.06 & 0.01 & 0.07 & 0.20 & $1985-2001$ \\
& & & & & &
\end{tabular}

Source: Bassanini and Duval (2006).

the expenditures on labor market training stayed constant at a low level of $0.03 \%$. Similar differences occur with respect to the public expenditures on subsidized jobs. In Belgium these expenditures were always at a high 0.6$0.8 \%$ of GDP while in Ireland and Sweden there was a major increase from about $0.25 \%$ in the second half of the 1980 s to $0.8-0.85 \%$ in the second half of the 1990s.

An overview of the dependent variable in our analysis, the unemployment rate of prime age workers (aged 25-54), is given in Table 2. ${ }^{4}$ As shown over the period of analysis there is a wide variation in the unemployment rate ranging from a low $2.9 \%$ in Switzerland to as high as $15.4 \%$ in Spain. We estimate the parameters of Eq. 1, where we investigate the effects of the additional labor market institutions, namely unemployment benefits, taxes, union density and employment protection legislation (EPL). Table 2 gives an over-

4 Alternatively we used the unemployment rate of age group 15-64 years but the results were very similar. 
TABLE 2 - CHARACTERISTICS OF LABOR MARKETS; AVERAGES

Unempl. rate Repl. rate Taxes Union density EPL High Corp.

\begin{tabular}{lrrrrrl}
\hline 1. Australia & 6.1 & 25.5 & 15.3 & 35.5 & 1.0 & 0.35 \\
2. Austria & 3.6 & 30.5 & 25.8 & 43.0 & 2.2 & 1.0 \\
3. Belgium & 7.7 & 40.6 & 39.0 & 54.2 & 2.9 & 1.0 \\
4. Canada & 8.0 & 17.9 & 19.6 & 32.0 & 0.8 & 0.0 \\
5. Denmark & 6.5 & 55.8 & 32.3 & 76.1 & 1.9 & 1.0 \\
6. Finland & 7.8 & 35.6 & 37.9 & 75.5 & 2.2 & 1.0 \\
7. France & 9.3 & 37.6 & 38.4 & 10.5 & 2.9 & 0.0 \\
8. Germany & 6.9 & 27.4 & 34.1 & 29.9 & 2.9 & 1.0 \\
9. Ireland & 12.8 & 28.9 & 27.6 & 48.9 & 0.9 & 0.8 \\
10. Italy & 8.3 & 22.2 & 40.3 & 36.9 & 3.1 & 0.8 \\
11. Japan & 2.6 & 10.3 & 16.4 & 24.1 & 2.0 & 1.0 \\
12. Netherlands & 5.9 & 53.3 & 36.7 & 25.1 & 2.6 & 1.0 \\
13. New Zealand & 5.5 & 29.8 & 19.3 & 37.3 & 1.0 & 0.4 \\
14. Norway & 3.2 & 39.5 & 26.2 & 56.4 & 2.8 & 1.0 \\
15. Portugal & 4.8 & 35.0 & 27.0 & 31.5 & 3.9 & 0.0 \\
16. Spain & 15.4 & 35.5 & 32.5 & 13.5 & 3.4 & 0.0 \\
17. Sweden & 4.5 & 27.2 & 42.0 & 81.3 & 2.9 & 0.0 \\
18. Switzerland & 2.9 & 28.7 & 18.1 & 23.1 & 1.1 & 1.0 \\
19. United Kingdom & 7.0 & 18.0 & 24.3 & 37.0 & 0.6 & 0.0 \\
20. United States & 4.6 & 12.5 & 24.1 & 14.9 & 0.2 & 0.0
\end{tabular}

Note: the averages are calculated over the time periods presented in Table 1. Source: Bassanini and Duval (2006).

view of country averages for these labor market institutions. As shown unemployment benefits - in terms of replacement rate - vary from a low $10.3 \%$ in Japan to a high $55.8 \%$ in Denmark. Tax rates vary from a low $24.1 \%$ in the United States to a high $42 \%$ in Sweden. Union density has a wide range from a low $10.5 \%$ in France to a high $81.3 \%$ in Sweden. The indicator for EPL varies from a low 0.2 in the US to a high 3.9 in Portugal. Finally, we use a dummy variable for high corporation in wage bargaining. As shown in a lot of countries this dummy variable has a value of 0 or 1 over the whole calendar time range indicating that no change occurred.

\subsection{Parameter Estimates}

As indicated before, in the analysis of how ALMP affects the unemployment rate an important problem, perhaps the main problem, is the possible endogeneity of ALMP. ALMP may have a negative effect on the unemployment rate but increasing unemployment may induce the government to expand expenditures on ALMP. As is clear from the literature overview there is no 
standard solution to the endogeneity problem. Often the problem has been addressed by using country averages of ALMP spending and assuming that the country effects are randomly distributed. This is unlikely to be correct since the country effects will not be independent from other country characteristics like labor market institutions. We will use an alternative solution. We use the shares of separate ALMP categories in total expenditures as explanatory variables. Whereas the level of expenditures may be subject to an endogeneity bias the shares are not. After all, there is no particular reason why an increase in unemployment would automatically lead to a different distribution of ALMP expenditures. ${ }^{5}$

The share of expenditures on labor market training is defined as:

$$
s t r_{i, t}=\frac{t r_{i, t}}{a l_{i, t}} \overline{a l}_{i}
$$

where $t r$ is the expenditures on labor market training, al is the sum of all ALMP expenditures and $\overline{a l}_{i}$ is the average of this variable over the period. The shares of expenditures on PES and subsidized jobs are defined accordingly. The time series variation allows us to use country-specific fixed effects. ${ }^{6}$

The first column of Table 3 shows the parameter estimates. Unemployment benefits and taxes have a positive effect on the unemployment rate while high corporate wage bargaining has a negative effect. Union density and employment protection do not have a significant effect on the unemployment rate. ${ }^{7}$ The main results concern the effects of the ALMP expenditures. As shown, the share of expenditures on labor market training has a negative effect on the unemployment rate. For the share of expenditures on PES we also find a negative effect, but the relevant parameter is insignificantly different from zero; the share of expenditures on subsidized jobs has a positive sign. So, the parameter estimates indicate that labor market training is the most effective ALMP in terms of reducing unemployment. This is confirmed in the second column of Table 3 which only contains the share of ALMP on training expenditures. Introducing the interaction between the share of expenditures on labor market training and unemployment benefits we find an additional significant negative effect (see column 3 of Table 3). Table 3 also shows that the parameter of the labor market institutions are not affected much by the change in the ALMP variables.

5 Bassanini and Duval (2006) use a more traditional instrumental variable approach finding similar results as we do.

6 Because of the collapse of the Soviet Union and the re-unification of Germany for Finland, Germany and Sweden separate country fixed effects are used for the time periods 1985-1992 and 1993-2002. Therefore, for 20 countries we estimate 23 fixed effects.

7 Studies like for example Belot and van Ours (2001, 2004) and Nickell et al. (2005) do find significant effects of employment protection and union density, but they consider a much longer calendar time period (from 1960 onwards). 
TABLE 3 - PARAMETER ESTIMATES

\begin{tabular}{llll}
\hline & $(1)$ & $(2)$ & $(3)$ \\
\hline UB Replacement rate & $0.11(4.2)$ & $0.14(5.6)$ & $0.19(7.3)$ \\
Tax wedge & $0.21(6.5)$ & $0.21(6.6)$ & $0.19(6.2)$ \\
Union density & $0.03(1.4)$ & $0.02(0.7)$ & $0.03(1.2)$ \\
Employment protection legislation & $-0.40(1.2)$ & $-0.35(1.1)$ & $-0.44(1.4)$ \\
Level of wage bargaining & $-2.04(5.3)$ & $-1.91(4.9)$ & $-2.06(5.6)$ \\
ALMP expenditure shares & $-0.17(5.4)$ & $-0.14(6.1)$ & $-0.09(3.5)$ \\
Training & $0.25(3.2)$ & - & - \\
Subsidized jobs & $-0.00(0.5)$ & - & - \\
Public employment services & - & - & $-0.03(5.0)$ \\
Interaction & & & \\
Training $\times$ UB Repl. rate & & & \\
\hline
\end{tabular}

Note: The estimates are based on 314 observations of 20 countries using calendar year fixed effects and 23 country fixed effects; see Appendix B for a description of the variables; absolute $t$-statistics in parentheses.

Finally, if we estimate Eq. 1 for the employment population rate (instead of the unemployment rate) as the variable to be explained we find that TU is the only instrument to raise participation significantly, which is in line with the theory presented above.

\section{CONCLUSIONS}

We present a theoretical analysis of different types of active labor market policies intended to bring the unemployed back to work. To explain the dichotomy between empirical studies based on micro data that usually find small

(if any) effects of training on the job finding rate and macro studies that show that labor market training can be effective we perform a theoretical analysis. In our theoretical search-matching model we investigate under which conditions it makes sense to introduce training programs and under which conditions alternative ways to build up human capital of unemployed workers should be preferred. We show that even if a training program does not influence the job finding rate it may still reduce the unemployment rate because of its effect on the job separation rate. By improving the quality of the match between worker and job the inflow into unemployment is reduced. This may also explain the empirical puzzle that longer term evaluation studies are more positive about job-related training programs than short-term evaluation studies. Short-term studies focus on job finding rates while in longer term studies the effects on job duration have a bigger impact. 
Our explorative empirical analysis, based on data from 20 OECD countries, confirms these results. We find that an increase in expenditures on labor market training causes unemployment to fall. The effect of expenditures on labor market training is larger the higher unemployment benefits are. The other instruments, public employment services and subsidized jobs, do not reduce unemployment.

As this is in line with the predictions of the model, it suggests that indeed the main effect of ALMP on unemployment works via the quality of the job match and not via the job finding rate. Since training programs influence this channel directly, they are most effective. Note, however, that we did not analyze the costs and benefits of these programs. It can still be the case that although training programs reduce the unemployment rate, the benefits of this do not outweigh the costs.

\section{APPENDIX A: PROOFS OF THE RESULTS IN THE MAIN TEXT}

Proof of Proposition 1 We derive here the results for the training subsidy $\sigma_{\chi}$, the other derivations are similar. We start with the effect of $\sigma_{\chi}$ on $V_{u}$ (for given $\bar{s} m(\bar{\theta})$ ). Using the envelop theorem, we find the following expression

$$
\frac{\partial V_{u}}{\partial \sigma_{\chi}}=\frac{\chi(e)}{\rho+\bar{s} m(\bar{\theta})\left[\frac{(1-\beta) \rho}{\rho+\delta_{h}}-(1-e) \frac{\beta \rho+\delta_{h}}{\rho+\varepsilon+\delta_{l}}\left(\frac{\beta \rho+\delta_{l}}{\beta \rho+\delta_{h}}-\frac{\rho+\delta_{l}}{\rho+\delta_{h}}\right)\right]}>0
$$

The sign of this expression follows from the following inequalities:

$$
\begin{aligned}
& \frac{(1-\beta) \rho}{\rho+\delta_{h}}-(1-e) \frac{\beta \rho+\delta_{h}}{\rho+\varepsilon+\delta_{l}}\left(\frac{\beta \rho+\delta_{l}}{\beta \rho+\delta_{h}}-\frac{\rho+\delta_{l}}{\rho+\delta_{h}}\right) \\
& >\frac{(1-\beta) \rho}{\rho+\delta_{h}}-\frac{\beta \rho+\delta_{h}}{\rho+\delta_{l}}\left(\frac{\beta \rho+\delta_{l}}{\beta \rho+\delta_{h}}-\frac{\rho+\delta_{l}}{\rho+\delta_{h}}\right) \\
& =\frac{(1-\beta) \rho}{\rho+\delta_{h}}-\left(\frac{\beta \rho+\delta_{l}}{\rho+\delta_{l}}-\frac{\beta \rho+\delta_{h}}{\rho+\delta_{h}}\right) \\
& =\frac{1}{\rho+\delta_{h}}\left[(1-\beta) \rho-\left(\beta \rho+\delta_{l}\right) \frac{\rho+\delta_{h}}{\rho+\delta_{l}}+\beta \rho+\delta_{h}\right] \\
& =\frac{\rho+\delta_{h}}{\rho+\delta_{h}}\left[1-\frac{\beta \rho+\delta_{l}}{\rho+\delta_{l}}\right]>0
\end{aligned}
$$

Next we consider the effect of $\sigma_{\chi}$ on $e$.

$$
\left(1-\sigma_{\chi}\right) \chi^{\prime \prime}(e) \frac{\partial e}{\partial \sigma_{\chi}}=\chi^{\prime}(e)-\bar{s} m(\bar{\theta}) \frac{\beta \rho+\delta_{h}}{\rho+\varepsilon+\delta_{l}}\left(\frac{\beta \rho+\delta_{l}}{\beta \rho+\delta_{h}}-\frac{\rho+\delta_{l}}{\rho+\delta_{h}}\right) \frac{\partial V_{u}}{\partial \sigma_{\chi}}
$$


Hence we find $\frac{\partial e}{\partial \sigma_{x}}>0$ if and only if

$$
\frac{\chi^{\prime}(e)}{\chi(e)}>\frac{\bar{s} m(\bar{\theta}) \frac{\beta \rho+\delta_{h}}{\rho+\varepsilon+\delta_{l}}\left(\frac{\beta \rho+\delta_{l}}{\beta \rho+\delta_{h}}-\frac{\rho+\delta_{l}}{\rho+\delta_{h}}\right)}{\rho+\bar{s} m(\bar{\theta})\left[\frac{(1-\beta) \rho}{\rho+\delta_{h}}-(1-e) \frac{\beta \rho+\delta_{h}}{\rho+\varepsilon+\delta_{l}}\left(\frac{\beta \rho+\delta_{l}}{\beta \rho+\delta_{h}}-\frac{\rho+\delta_{l}}{\rho+\delta_{h}}\right)\right]}
$$

As shown above $\frac{(1-\beta) \rho}{\rho+\delta_{h}}>\frac{\beta \rho+\delta_{h}}{\rho+\varepsilon+\delta_{l}}\left(\frac{\beta \rho+\delta_{l}}{\beta \rho+\delta_{h}}-\frac{\rho+\delta_{l}}{\rho+\delta_{h}}\right)$, hence a sufficient condition for this inequality to hold is

$$
\frac{\chi^{\prime}(e)}{\chi(e)}>\frac{1}{1-(1-e)}=\frac{1}{e}
$$

which holds because of the assumptions $\chi(0)=0$ and $\chi^{\prime \prime}(e)>0$ as can be seen as follows. Using a Taylor expansion we can write

$$
\chi(0)=\chi(e)+\chi^{\prime}(e)(0-e)+\frac{1}{2} \chi^{\prime \prime}(\zeta)(0-e)^{2}
$$

for some $\zeta \in\langle 0, e\rangle$. Since $\chi(0)=0$ and $\chi^{\prime \prime}(\cdot)>0$ we see that $\chi^{\prime}(e) e>\chi(e)$ which is the required inequality.

Finally, consider the interaction effect. The effect of $b$ on $u$ can be written as

$$
\frac{\partial u}{\partial b}=\frac{-\frac{s m(\theta)}{\delta_{h}\left(\varepsilon+\delta_{l}\right)}\left(\delta_{l}-\delta_{h}\right)}{\left(1+\frac{s m(\theta)}{\delta_{h}\left(\varepsilon+\delta_{l}\right)}\left(\delta_{h}+\varepsilon+e\left(\delta_{l}-\delta_{h}\right)\right)\right)^{2}} \frac{\partial e}{\partial b}>0
$$

since $\frac{\partial e}{\partial b}<0$. Differentiating this with respect to $\sigma_{\chi}$ yields

$$
\begin{aligned}
\frac{\partial^{2} u}{\partial b \partial \sigma_{\chi}}= & 2 u^{3}\left(\frac{s m(\theta)}{\delta_{h}\left(\varepsilon+\delta_{l}\right)}\left(\delta_{l}-\delta_{h}\right)\right)^{2} \frac{\partial e}{\partial b} \frac{\partial e}{\partial \sigma_{\chi}} \\
& -u^{2} \frac{s m(\theta)}{\delta_{h}\left(\varepsilon+\delta_{l}\right)}\left(\delta_{l}-\delta_{h}\right) \frac{\partial^{2} e}{\partial b \partial \sigma_{\chi}}
\end{aligned}
$$

since $\frac{\partial e}{\partial b}<0$ and $\frac{\partial e}{\partial \sigma_{\chi}}>0$ we find that a sufficient condition for $\frac{\partial^{2} u}{\partial b \partial \sigma_{\chi}}<0$ is that $\frac{\partial^{2} e}{\partial b \partial \sigma_{\chi}}>0$. This second (cross) derivative can be written as

$$
\begin{aligned}
\left(1-\sigma_{\chi}\right) \chi^{\prime \prime}(e) \frac{\partial^{2} e}{\partial b \partial \sigma_{\chi}}= & \overbrace{\chi^{\prime \prime}(e) \frac{\partial e}{\partial b}-\left(1-\sigma_{\chi}\right) \chi^{\prime \prime \prime}(e) \frac{\partial e}{\partial b} \frac{\partial e}{\partial \sigma_{\chi}}}^{(a)} \\
& \underbrace{-\bar{s} m(\bar{\theta}) \frac{\beta \rho+\delta_{h}}{\rho+\varepsilon+\delta_{l}}\left(\frac{\beta \rho+\delta_{l}}{\beta \rho+\delta_{h}}-\frac{\rho+\delta_{l}}{\rho+\delta_{h}}\right) \frac{\partial^{2} V_{u}}{\partial b \partial \sigma_{\chi}}}
\end{aligned}
$$


where

$$
\frac{\partial^{2} V_{u}}{\partial b \partial \sigma_{\chi}}=-\left(\frac{\partial V_{u}}{\partial b}\right)^{2} \bar{s} m(\bar{\theta}) \frac{\beta \rho+\delta_{h}}{\rho+\varepsilon+\delta_{l}}\left(\frac{\beta \rho+\delta_{l}}{\beta \rho+\delta_{h}}-\frac{\rho+\delta_{l}}{\rho+\delta_{h}}\right) \frac{\partial e}{\partial \sigma_{\chi}}<0
$$

because $\frac{\partial e}{\partial \sigma_{\chi}}>0$. Hence the sign of $\frac{\partial^{2} e}{\partial b \partial \sigma_{\chi}}$ is determined by three terms. The first, is negative as $\frac{\partial e}{\partial b}<0$. The second and third are positive. A sufficient condition for $(b)$ to dominate $(a)$ is that $\chi^{\prime \prime \prime}(e)$ is big.

\section{APPENDIX B: DATA}

All data are from Bassanini and Duval (2006), where more details of the data can be found. The following variables were used:

- Unemployment rate: Unemployed workers as share of the labor force, in $\%$; 25-54 age group.

- UB Replacement rate: Average unemployment benefit replacement rate across two income situations (100 and 67\% of average production worker earnings), three family situations (single, with dependent spouse, with spouse in work) and three different unemployment durations (first year, second and third year, and fourth and fifth year of unemployment).

- Tax wedge: The wedge between the labor cost to the employer and the corresponding net take-home pay of the employee for a single-earner couple with two children earning $100 \%$ of average production worker earnings. The tax wedge expresses the sum of personal income tax and all social security contributions as a percentage of total labor cost.

- Union density: Share of workers affiliated to a trade union, in $\%$.

- Employment Protection Legislation: OECD summary indicator of the stringency of Employment Protection Legislation.

- Level of wage bargaining: High degree of centralization/co-ordination of the wage bargaining processes.

- ALMP: Public expenditures on active labor market programs per unemployed worker as a share of GDP per capita.

- Training: Public expenditures on labor market training per unemployed worker as a share of GDP per capita. Labor market training involves training for unemployed adults and those at risk, training for employed adults. The expenditures include both course costs and subsistence allowances, but special training programs for youth and disabled are excluded.

- Subsidized jobs: Public expenditures on subsidized employment per unemployed worker as a share of GDP per capita. Subsidized employment concerns targeted measures to promote or provide employment for the unemployed and other priority groups (but not youth and the disabled). It also concerns wage subsidies paid to private sector firms to encourage the 
recruitment of targeted workers or continued employment of those whose jobs are at risk and concerns support of unemployed persons starting enterprizes and direct job creation (in public or non-profit organizations) to benefit the unemployed.

- PES: Public expenditures on public employment services and administration per unemployed worker as a share of GDP per capita. The expenditures concern placement, counseling and vocational guidance, job-search courses, assistance with displacement costs, administering unemployment benefits, all other administration costs of labor market agencies including running labor market programs.

Open Access This article is distributed under the terms of the Creative Commons Attribution Noncommercial License which permits any noncommercial use, distribution, and reproduction in any medium, provided the original author(s) and source are credited.

\section{REFERENCES}

Bassanini, A. and R. Duval (2006), 'Employment patterns in OECD countries: reassessing the role of policies and institutions,' OECD Economics Department Working Papers No. 486, Paris.

Belot, M. and J.C. van Ours (2001), 'Unemployment and labor market institutions: an empirical analysis,' Journal of Japanese and International Economics, 15, pp. 1-16.

Belot, M. and J.C. van Ours (2004), 'Does the recent success of some OECD countries in lowering their unemployment rate lie in the clever design of their labor market reforms?' Oxford Economic Papers, 56, pp. 621-642.

Blanchard, O. and J. Wolfers (2000), 'The role of shocks and institutions in the rise of European unemployment: The aggregate evidence,' Economic Journal 110, pp. 1-33.

Card, D., J. Kluve and A. Weber (2009) 'Active labor market policy evaluations: a meta-analysis', Working Paper, no. 4002, IZA, Bonn.

Elmeskov, J., J.P. Martin and S. Scarpetta (1998), 'Key lessons for labor market reforms: evidence from OECD countries' experiences,' Swedish Economic Policy Review 5, pp. 205-252.

Kluve, J. and C.M. Schmidt (2002), 'Can training and employment subsidies combat European unemployment?' Economic Policy, 35, pp. 411-448.

Kluve, J. (2007), 'The effectiveness of European ALMP's', in: J Kluve et al. Active Labor Market Policies in Europe: Performance and Perspectives, Berlin and Heidelberg, Springer, pp. 153-203.

Mortensen, D.T. and C.A. Pissarides (1999), 'New developments in models of search in the labor market,' in O. Ashenfelter and D. Card (eds.) Handbook of Labor Economics, Amsterdam, Elsevier.

Nickell, S.J. and R. Layard (1999), 'Labor market institutions and economic performance,' in O. Ashenfelter and D. Card (eds.) Handbook of Labor Economics, Elsevier, Amsterdam.

Nickell, S.J., L. Nunziata and W. Ochel (2005), 'Unemployment in the OECD since the 1960s; what do we know?,' Economic Journal, 115, pp. 1-27.

Organization for Economic Cooperation and Development (1994) The OECD jobs study, Part II, OECD, Paris. 
Organization for Economic Cooperation and Development (1997) Employment Outlook, OECD, Paris.

Organization for Economic Cooperation and Development (2005) Employment Outlook, OECD, Paris.

Organization for Economic Cooperation and Development (2006) Employment Outlook, OECD, Paris.

Scarpetta, S. (1996), 'Assessing the role of labor market policies and institutional settings on unemployment: a cross-country study,' OECD Economic Studies 26, pp. 43-98.

Van Ours, J.C. (2004), 'The locking-in effect of subsidized jobs,' Journal of Comparative Economics, 32, pp. 37-52. 